\title{
Nitric oxide and coronary vascular endothelium adaptations in hypertension
}

This article was published in the following Dove Press journal:

Vascular Health and Risk Management

12 December 2009

Number of times this article has been viewed

\section{Andrew S Levy* Justin CS Chung* Jeffrey T Kroetsch* James WE Rush}

Department of Kinesiology, University of Waterloo, Waterloo, Ontario, Canada; *These authors contributed equally to this work
Correspondence: James WE Rush Department of Kinesiology, University of Waterloo, Waterloo, Ontario,

Canada N2L 3GI

$\mathrm{Tel}+$ I 5198884567, Ext 32126

Fax +I 5198850470

Email jwerush@uwaterloo.ca
Abstract: This review highlights a number of nitric oxide (NO)-related mechanisms that contribute to coronary vascular function and that are likely affected by hypertension and thus become important clinically as potential considerations in prevention, diagnosis, and treatment of coronary complications of hypertension. Coronary vascular resistance is elevated in hypertension in part due to impaired endothelium-dependent function of coronary arteries. Several lines of evidence suggest that other NO synthase isoforms and dilators other than NO may compensate for impairments in endothelial NO synthase (eNOS) to protect coronary artery function, and that NO-dependent function of coronary blood vessels depends on the position of the vessel in the vascular tree. Adaptations in NOS isoforms in the coronary circulation to hypertension are not well described so the compensatory relationship between these and eNOS in hypertensive vessels is not clear. It is important to understand potential functional consequences of these adaptations as they will impact the efficacy of treatments designed to control hypertension and coronary vascular disease. Polymorphisms of the eNOS gene result in significant associations with incidence of hypertension, although mechanistic details linking the polymorphisms with alterations in coronary vasomotor responses and adaptations to hypertension are not established. This understanding should be developed in order to better predict those individuals at the highest risk for coronary vascular complications of hypertension. Greater endothelium-dependent dilation observed in female coronary arteries is likely related to endothelial $\mathrm{Ca}^{2+}$ control and eNOS expression and activity. In hypertension models, the coronary vasculature has not been studied extensively to establish mechanisms for sex differences in NO-dependent function. Genomic and nongenomic effects of estrogen on eNOS and direct and indirect antioxidant activities of estrogen are discussed as potential mechanisms of interest in coronary circulation that could have implications for sex- and estrogen status-dependent therapy for hypertension and coronary dysfunction. The current review identifies some important basic knowledge gaps and speculates on the potential clinical relevance of hypertension adaptations in factors regulating coronary NO function.

Keywords: eNOS, oxidative stress, polymorphism, sex effect, artery, estrogen

\section{Introduction to coronary hemodynamics in hypertension}

Coronary blood flow is highly regulated to ensure an adequate matching of coronary perfusion to meet the metabolic demands imposed by a constantly beating heart. ${ }^{1-4}$ The main mechanisms controlling coronary artery tone are: metabolic, myogenic, neurohormonal, and endothelial. ${ }^{1,3,4}$ These factors all interact to determine myocardial perfusion, and the relative importance of each mechanism varies as a function of 
the anatomical location of the vessel type of interest in the vascular tree. For instance, large coronary arteries have a greater dependency on endothelium-dependent mechanisms for maintenance of proper tone, while smaller arterioles depend more on metabolic and myogenic mechanisms. ${ }^{2,5,6}$ Vascular resistance is dependent on position in the vascular network with approximately $75 \%$ of the resistance lying in the arteries between $75-200 \mu \mathrm{m}$ in diameter, ${ }^{2,5,7}$ and resistance also varies depending on the location of the vasculature within the depth of the myocardium. ${ }^{2,5,8}$

Several human ${ }^{9-12}$ and experimental animal ${ }^{13-22}$ studies indicate that coronary vascular resistance is increased, and coronary flow reserve is decreased with hypertension. The pathophysiology of hypertension is undoubtedly heterogeneous and a variety of animal models have been developed to investigate essential hypertension. The spontaneously hypertensive rat (SHR) model has been particularly useful since several defining characteristics of the SHR are similar to those observed in human essential hypertension including hemodynamic abnormalities, humoral and sympathetic nervous system involvement, renal abnormalities and vascular cellular adaptations. ${ }^{23-28}$ For example, even though SHR can have similar coronary blood flow compared to their normotensive counterpart Wistar-Kyoto rats (WKY) on a ventricular mass-corrected basis, ${ }^{13}$ SHRs have higher coronary vascular resistance (CVR) over a wide pressure range, ${ }^{14,19}$ and higher minimal CVR (lower maximal conductance) during maximal coronary vasodilation. ${ }^{13,16}$

Changes in coronary hemodynamics accompanying hypertension occur as a result of both structural and functional adaptations in the coronary vasculature. Structural remodeling to hypertension includes hypertrophic and eutrophic inward remodeling and frank rarefaction, which can result in loss of up to half of the normal number of microvessels. ${ }^{29,30}$ A number of genetic, neurohumoral, and local factors contribute..$^{9,11,19,29-36}$ to these adaptations which result in increases in resistance, as well as reduced flow and increased diffusion distances, all of which impair oxygen delivery and organ function. Although nitric oxide (NO) likely contributes to the structural remodeling accompanying hypertension, the focus of this review does not include description of structural adaptations, and the reader is referred to other works dealing with these topics. ${ }^{29,30,34,35}$ Rather, the current focus is on the contribution of vascular NO to the functional adaptations in the coronary circulation in hypertension.

Multiple endothelium-derived products may contribute to the control of the coronary vasculature. ${ }^{37,38}$ For instance, it is quite apparent that one or more endothelium-derived hyperpolarizing factors (EDHFs) contribute greatly to the control of the coronary microcirculation. ${ }^{39}$ Potentially important compensatory roles for EDHF may make these factors even more dominant in coronary vascular regulation under conditions of impairment of NO bioavailability. ${ }^{40-46}$ The importance and emerging knowledge concerning EDHF notwithstanding, the focus of the current review is on NO and coronary adaptations to hypertension, and the reader is referred to the cited works for further information on EDHF in the coronary vasculature.

Several reports have suggested that altered NO bioavailability contributes to altered vasomotion seen in hypertension $^{38,47,48}$ and NO is the primary dilator of large epicardial coronary arteries ${ }^{3,6,49}$ as well as a mediator of flowinduced dilation in the coronary microcirculation. ${ }^{2,5,6}$ Given the potential importance of the NO system in the etiology of hypertensive large artery disease, and given the fact that studies in other vascular beds have revealed a number of patterns of regulation of the NO system, the importance of which is not known in the coronary bed and in hypertension, it is important to bring attention to these factors as they may be important clinically and therapeutically. Thus, this review attempts to highlight a number of factors that influence NO function and which may be relevant from both basic science and clinical perspectives of understanding the function of the coronary circulation in hypertension.

\section{Nitric oxide bioavailability in the control of coronary hemodynamics in hypertension}

The NO synthase (NOS) inhibitor $N^{\omega}$-nitro-L-arginine methyl ester (L-NAME) has been a useful tool in studies determining the NO component of flow and CVR alterations in the intact coronary circulation. Reductions in baseline coronary flow in the presence of L-NAME were smaller in SHR than in WKY hearts, ${ }^{19,22}$ suggesting a reduced basal NO bioavailability in the coronary circulation of hypertensive animals. NO bioavailability is a function of the production and destruction of NO, and of the sensitivity of the target tissue to NO.$^{48}$ Further investigation revealed that the smaller L-NAME-dependent reduction in baseline coronary flow was not correlated to decreases in NO production, suggesting that increased destruction of NO and/or decreased sensitivity to NO contributed to the reduced basal coronary NO bioavailability in hypertension. ${ }^{22}$

In contrast to baseline effects, acetylcholine (ACh)stimulated dilation of the coronary circulation was similar in normotensive and hypertensive animals, and was abolished in 
both groups by L-NAME, suggesting stimulated NO release and/or bioavailability may be unaltered by hypertension in this vascular bed.$^{50}$ Further analysis revealed, however, that the relationship between CVR and NO production is altered in SHR hearts so a greater amount of NO production occurs despite a persistently much higher CVR than in WKY controls..$^{18}$ Furthermore, inhibition of eNOS with L-arginine analogues also blunts constrictory responses in the majority of the coronary perfusion studies in hypertensive hearts, ${ }^{19,21}$ suggesting that $\mathrm{NO}$ is contributing to constrictory responses in the hypertensive coronary vascular bed likely via its destruction by superoxide and the consequent effects of reactive species formed. ${ }^{51}$ This is supported by observations that supplementation of the coronary perfusate with the superoxide scavenging enzyme superoxide dismutase restored the maximal endothelium-dependent dilation in hypertensive animals. ${ }^{21}$ Sensitivity to NO is likely not altered in hypertensive perfused heart studies, ${ }^{18,21,22}$ acknowledging some dissenting reports. ${ }^{52}$ Together this evidence suggests that increased NO destruction is a dominant contributor to the reduced NO bioavailability and consequent elevated CVR in the intact coronary circulation of hypertensive animals.
Complementary work using isolated blood vessels reveals additional details regarding potential mechanisms accounting for hypertensive adaptations in the coronary circulation.

\section{Nitric oxide-mediated vasomotor function of isolated coronary arteries in hypertension}

Studies using isolated coronary arteries and arterioles support the findings from the intact coronary circulation that endothelium-dependent dilatory function is impaired in hypertensive animals, and that reduced NO bioavailability, and increased oxidative stress contribute to the mechanism of this impairment (Figure 1). Indeed, in general, endothelium-mediated (drug- and shear stress-stimulated) dilation of isolated coronary arteries is reduced in hypertensive humans ${ }^{11,53-57}$ and animals, ${ }^{19,21,32,36,45,51,52,58-62}$ while the endothelium-independent vasodilatory responses to sodium nitroprusside and adenosine are often unaltered. ${ }^{21,32,45,55,63}$ There are exceptions to these general observations ${ }^{18,33,50,63-66}$ and the vessel type (conduit vs resistance artery), ${ }^{45,57}$ the mode of precontraction, ${ }^{33}$ and the vasodilator protocol ${ }^{45,64}$

\section{Hypertension}

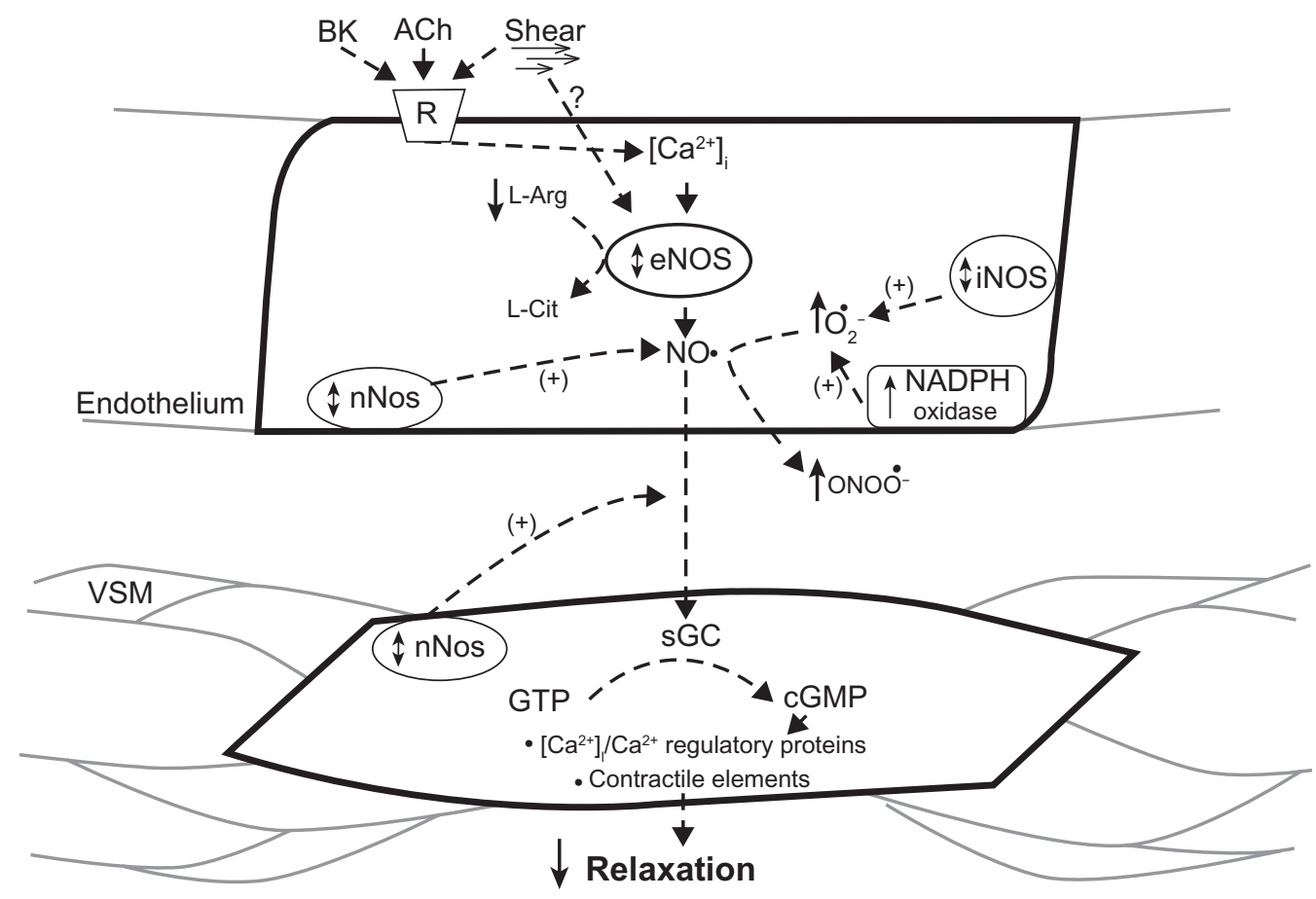

Figure I Factors affecting NO-mediated endothelium-dependent relaxation of coronary arteries in hypertension. Chemical and hemodynamic forces on the luminal side of the endothelium stimulate eNOS production of NO which can be scavenged by superoxide or diffuse to the vascular smooth muscle cells. At the smooth muscle, available NO activates sGC ultimately affecting $\mathrm{Ca}^{2+}$ regulatory proteins, cytosolic $\left[\mathrm{Ca}^{2+}\right]$, and contractile elements, thereby causing arterial relaxation. In hypertension, $\mathrm{NO}$-bioavailability and relaxation of the coronary vascular smooth muscle can be altered due to many factors as discussed in the text and indicated in the Figure by the small arrows.

Abbreviations: BK, bradykinin; ACh, acetylcholine; R, receptor; L-Arg, L-Arginine; L-Cit, L-Citrulline; eNOS, endothelial nitric oxide synthase; iNOS, inducible nitric oxide synthase; nNOS, neuronal nitric oxide synthase; NO*, nitric oxide; O2*-, superoxide; ONOO-, peroxynitrite; VSM, vascular smooth muscle; sGC, soluble guanylate cyclase. 
must be scrutinized to compare and analyze mechanisms of coronary vasomotor control.

Agonist-induced dilation from the pre-contracted state is reduced s5,56,61,67 $^{\text {or eliminated }}{ }^{58,68,69}$ by inhibitors of eNOS in isolated coronary vessels from hypertensive animals, suggesting that NO remains an important component of vascular function even when its bioavailability is reduced in hypertension. In isolated pressurized coronary microvessels it was observed that removal of the endothelium increased the amount of myogenic constriction to a greater extent in SHR than in WKY over a wide pressure range. ${ }^{31}$ Similarly, inhibition of the endothelial NOS isoform eNOS resulted in greater constriction in the SHR at moderate-to-high pressures, ${ }^{31}$ while inhibition of the cyclooxygenase (COX) pathway did not affect the myogenic response in either WKY or SHR. ${ }^{70}$ These studies suggest that NO is an important mediator of basal tone, especially at higher pressures, which are more likely to be physiologically relevant, especially in hypertension.

Regarding NO bioavailability in isolated arteries, while several reports suggest that NO production per se is not altered in isolated arteries from hypertensive animals, ${ }^{18,22,66}$ a recent report indicates that hypertension is associated with an increase in arginase activity, which results in reduced basal and stimulated NO production. ${ }^{71}$ In general, however, increased local vascular superoxide production-induced destruction of NO is thought to be the major mechanism limiting NO bioavailability in isolated coronary vessels from hypertensive animals, ${ }^{48,72}$ as also seemed to be the case when evaluating the intact coronary vascular bed.

The reaction rate of $\mathrm{NO}$ and superoxide is much faster than that of superoxide with superoxide dismutase. ${ }^{47}$ Thus it is not surprising that in hypertension the increased production of reactive oxygen species (ROS) is associated with an increased production of peroxynitrite in the heart and coronary blood vessels. ${ }^{47,48,73-75}$ The production of peroxynitrite itself has an impact on several pathways of vasodilation including reduced prostaglandin synthesis and inhibition of $\mathrm{K}^{+}$channels. ${ }^{8,76}$ Additionally peroxynitrite impairs NO production through oxidation of $\mathrm{BH}_{4}$, a NOS co-factor ${ }^{8,76-78}$ and also impairs the $\mathrm{sGC}$-mediated response to $\mathrm{NO} .^{8,76}$

\section{Coronary hemodynamics and vasomotor activity in the eNOS knockout mouse}

Given that hypertension is associated with impairments in NO bioavailability in the coronary vasculature as illustrated above, it is instructive to consider whether experimental models that specifically disrupt NO availability can provide insight to help understand and interpret hypertensive adaptations. One such model is the eNOS knockout mouse. Early work by Huang and colleagues demonstrated an increase in blood pressure $(-20 \mathrm{~mm} \mathrm{Hg})$ in eNOS knockout $\left(\mathrm{eNOS}^{--}\right.$) compared to wild-type (WT) mice, ${ }^{79}$ and subsequent studies have demonstrated that the blood pressure effect is age-dependent; absent at eight weeks, but elevated by up to $\sim 50 \mathrm{~mm} \mathrm{Hg}$ at 12 weeks. ${ }^{80,81}$ These observations are consistent with the general view that NO is of critical importance in controlling vascular resistance and blood pressure.

The coronary vasculature of WT mice depends on NO for the majority of its overall total endothelium-dependent dilation since acute NOS inhibition eliminates most of the ACh-induced dilation in isolated preparations of the left anterior descending and left circumflex coronary arteries ${ }^{82,83}$ and about half of the bradykinin (BK)-induced dilation in isolated heart preparations. ${ }^{44}$ However, in the $\mathrm{eNOS}^{-/}$, overall total endothelium-dependent dilation of the coronary vasculature can be either unaltered, ${ }^{83}$ reduced, ${ }^{44}$ or eliminated ${ }^{82}$ when compared to WT littermates. Since dilatory responses to endothelium-independent dilators in $\mathrm{eNOS}^{-/}$are identical to those in WT in both isolated vessels ${ }^{82,83}$ and perfused heart preparations, ${ }^{40,44}$ these results suggest that alterations occur in the $\mathrm{eNOS}^{-/-}$as a result of changes in the activity of other endothelium-derived vasodilators to compensate for the loss of eNOS-derived NO.

Little consensus has been reached as to the chemical identity of the dilator(s) released from the endothelium in $\mathrm{eNOS}^{-/}$. Possibilities include NO (derived from other NOS isoforms; iNOS, nNOS), prostacylin, and non-NO, nonprostanoid endothelium-derived dilators. ${ }^{42}$ For instance, in isolated coronary arteries, the specific nNOS inhibitor trifluoromethylphenylimidazole (TRIM) significantly reduced $\mathrm{ACh}$-induced dilation in $\mathrm{eNOS}^{-/-}$by approximately half, and additional COX inhibition with indomethacin almost completely eliminated this remaining ACh-induced dilation. In contrast, neither inhibitor affected the responses in WT vessels. ${ }^{83}$ This suggests that nNOS-derived NO and prostacyclin may compensate for the loss of eNOS in $\mathrm{eNOS}^{-/}$ to preserve coronary artery endothelium-dependent dilation. It is also possible that upregulation of cytochrome-P450 metabolites may be responsible for some of the compensatory endothelium-dependent dilation observed in the $\mathrm{NOS}^{-/-}$ coronary vasculature. ${ }^{44}$

Thus, although it is clear that overall endothelium-dependent dilation may be maintained in $\mathrm{eNOS}^{-/-}$via compensatory 
changes in alternate dilatory pathways, the precise mechanisms signaling this compensation by alternate pathways is not resolved and seems to involve multiple factors. ${ }^{42}$ The hypertension itself, and the compensatory changes in endotheliumderived vasoactive pathways that occur in the $\mathrm{eNOS}^{-/}$model must be accounted for in studies utilizing this model to study the importance of eNOS and adaptations of the coronary circulation to hypertension. Known responses of NOS isoforms in hypertension may help to determine the mechanisms controlling compensatory responses in the regulation of coronary endothelial function. It could be important to understand this issue for the effective clinical/therapeutic management of vascular dysfunction in hypertension and other cardiovascular disease.

\section{Adaptations in coronary NOS isoforms to hypertension}

The NOS family of enzymes is composed of three isoforms; neuronal nNOS, inducible iNOS, and endothelial eNOS. ${ }^{84}$ For all isoforms, NO production is controlled through protein expression level, and a number of post-translational mechanisms; however, many regulatory mechanisms are isoform-specific. ${ }^{84}$ In terms of coronary vascular control in hypertension and heart failure, eNOS is the major isoform of interest, and is expressed in the coronary endothelium, the endocardium, and in cardiomyocytes,${ }^{85,86}$ however, $\mathrm{nNOS}$ and iNOS may also play a role in vascular control under certain conditions (Figure 1), ${ }^{87-90}$ as alluded to above. ${ }^{83}$

\section{eNOS}

Observations that eNOS expression level of coronary artery endothelium, ${ }^{52}$ and intramyocardial arterioles ${ }^{19}$ are reduced in SHR vs WKY animals have led to the suggestion that reduced eNOS expression contributes to the coronary endothelial dysfunction accompanying hypertension. However, other studies report that eNOS expression is actually increased in the coronary vessels in hypertension, suggesting that compensatory upregulation of this enzyme may be a strategy to help preserve vascular function. ${ }^{85}$

In contrast to the disparate findings regarding coronary eNOS expression in hypertension, ${ }^{19,52,85,88}$ eNOS levels in large systemic arteries such as the aorta are generally increased in hypertensive rats. ${ }^{48}$ For example, eNOS protein expression was elevated by $\sim 60 \%$ in male SHR compared to WKY thoracic aorta. ${ }^{91}$ Although eNOS expression is elevated in the SHR aorta, the elevated ROS environment because of increased $\mathrm{NAD}(\mathrm{P}) \mathrm{H}$ oxidase expression ${ }^{48}$ may scavenge the available NO, and/or uncoupled eNOS could be producing ROS rather than $\mathrm{NO},{ }^{92}$ both of which would lead to the impaired NO-mediated dilation. The importance of these mechanisms in the coronary circulation in hypertension has not been resolved. In this regard, it will be important to assess the susceptibility of the coronary vascular bed to ROS-mediated reductions in NO bioavailability in hypertension via the actions of ROS sources such as NADPH oxidase and possibly uncoupled NOS activity.

Uncoupled eNOS has been the subject of several extensive reviews. ${ }^{76-78,93}$ Briefly, this process is a result of reduced substrate L-arginine or cofactor $\mathrm{BH}_{4}$. Under either of these conditions the flow of electrons is delivered to molecular oxygen and superoxide is formed. ${ }^{76-78,93}$ In hypertensive animals chronic treatment with $\mathrm{BH}_{4}$ has been shown to improve endothelium-dependent dilation though this treatment both increased NO production and reduced superoxide production. ${ }^{74,94}$ These results suggest that at least part of the increased production of ROS and altered vasodilation may be explained by increased uncoupled eNOS-mediated production of superoxide, and subsequent reduced NO bioavailability. The reduction in $\mathrm{BH}_{4}$ and/or increase in $\operatorname{arginase}^{71}$ may propagate the uncoupling of eNOS and enhance superoxide production under these conditions. It needs to be determined if uncoupled eNOS contributes to suppression of NO bioavailability in the coronary vascular bed in hypertension in order to determine if this should be a potentially important treatment target to correct the vascular dysfunction.

\section{iNOS}

The potential role for iNOS as a vasoactive NO source in the coronary vasculature of hypertensive animals is supported by observations of increased iNOS expression in many SHR tissues (including heart) which is attenuated by antioxidant treatment ${ }^{88}$ However, other studies show that iNOS activity is either no different between SHR and WKY, ${ }^{85}$ or completely undetectable in either strain. ${ }^{95}$ Similarly, in dogs with acute perinephritic hypertension, iNOS protein is undetectable in the heart and no difference in $\mathrm{Ca}^{2+}$-independent NOS activity is apparent between normotensive and hypertensive conditions. ${ }^{86}$ Thus, the contribution of iNOS to altered NO production in hypertension remains unknown at this time. The involvement of iNOS may be complex, as this isoform is known to act in an uncoupled manner, producing superoxide in some diseased arteries (Figure 1). ${ }^{90}$ It is also possible that the reduction in both $\mathrm{BH}_{4}$ and L-arginine could account for increased superoxide production from uncoupled iNOS, as described above for eNOS. 


\section{nNOS}

Isolated left anterior descending coronary arteries from eNOS $^{-/-}$exhibit similar overall total endothelium-dependent dilation in response to increased flow as do those from WT. ${ }^{89}$ Flow-induced dilation of $\mathrm{eNOS}^{-/}$coronary arteries was inhibited by the nNOS specific inhibitor 7-nitroindazole (7-Ni), and by the soluble guanylate cyclase (sGC) inhibitor $1 \mathrm{H}-[1,2,4]$ oxadiazolo[4,3-a]quinoxalin-1-one (ODQ) to a similar extent as by L-NAME ${ }^{89}$ However, while L-NAME inhibited dilation in WT, 7-Ni had no effect in WT, suggesting that the vasodilatory role for nNOS-derived NO was limited to conditions under which $\mathrm{NO}$ availability from eNOS is impaired (ie, the eNOS ${ }^{-/}$), similar to the findings of a previous report that used the nNOS inhibitor TRIM to demonstrate a vasodilatory contribution of nNOS in isolated coronary arteries of $\mathrm{eNOS}^{-/}$but not WT. ${ }^{83}$ The presence of nNOS protein in the coronary endothelium of $\mathrm{NOS}^{-/}$, but not in WT animals ${ }^{89}$ supports the functional findings. Thus, in the absence of eNOS, nNOS may be upregulated, and act through sGC to help maintain coronary flow-mediated dilation. This reveals a possible compensatory role for nNOS in the control of coronary vascular function in hypertension, especially if the elevated blood pressure associated with $\mathrm{eNOS}^{-/-}$is involved in signaling the increase in nNOS expression. ${ }^{83}$

The work with knockout animals and with isoformspecific pharmacological blockade reveals that shifts can occur in the origin of $\mathrm{NO}$ in the coronary vasculature under conditions of impairment of eNOS function and of oxidative stress, such as occurs in a variety of cardiovascular diseases including hypertension. Currently, these adaptations are predominantly interpreted as compensatory changes to protect NO bioavailability under the indicated conditions. The findings highlight an important response that must be taken into account to understand the role of $\mathrm{NO}$ in coronary vascular adaptations to hypertension and in therapeutic interventions designed to protect coronary vascular function. Factors affecting individual variability in eNOS regulation could impact these considerations, including emerging evidence that gene polymorphisms in eNOS are associated with cardiovascular disease risk.

\section{eNOS polymorphisms associated with hypertension and coronary vascular function}

Gene polymorphisms in eNOS and resultant impacts on eNOS expression levels have been associated with increased risk of hypertension, ${ }^{96}$ as well as a variety of conditions affecting the coronary circulation including coronary artery disease and coronary spasm. ${ }^{97}$ However, little evidence is available regarding the precise mechanisms by which eNOS polymorphisms may lead to altered levels of cardiovascular disease. Although a variety of locus- and ethnicity-dependent polymorphism effects exist, ${ }^{97}$ the current review will briefly focus specifically on the single nucleotide polymorphisms and grouped haplotypes that are associated with hypertension, and the limited known effects on coronary vascular function (Figure 2).

An exon 7 polymorphism results in eNOS Glu298Asp, with the Glu298Asp variant associated with $2.3 \mathrm{X}$ greater odds of developing hypertension. ${ }^{96,97}$ Several recent studies also associate eNOS combined haplotypes of the T-786C, Glu298Asp, and intron 4 polymorphisms with incidence of hypertension and plasma NO metabolites, ${ }^{98,99}$ implying a functional change at the eNOS enzyme. Available information suggests that eNOS polymorphisms attenuate the eNOS promoter efficiency. ${ }^{100,101}$ However, combinations of single polymorphisms can interact in a complex manner, and this supports the need to investigate haplotypes in order to assess and understand the role of eNOS polymorphisms in hypertension and vascular function. ${ }^{101}$

Although eNOS polymorphisms and altered coronary eNOS expression are associated with hypertension, ${ }^{96,98,99}$ little direct evidence links mutations in the eNOS gene to specific mechanisms of coronary vascular dysfunction in hypertension. Certain polymorphisms for the $27 \mathrm{bp}$ repeat at intron 4 and for the G894T have been associated with alterations in coronary vasomotor responses, ${ }^{102,103}$ but this has not been assessed in a manner that allows for conclusions regarding the endothelium, or NO-dependency of the response. Thus, the precise mechanisms by which eNOS polymorphisms might affect coronary vascular function in hypertension have not yet been well established, and this important issue remains to be elucidated experimentally. In light of the involvement of NO in coronary hemodynamic and vasomotor adaptations to hypertension established in the previous sections, it is likely that human eNOS polymorphisms will be a factor contributing to the overall coronary vascular endothelial dysfunction accompanying hypertension in humans. Knowledge of the eNOS polymorphism status could be of possible diagnostic and therapeutic utility in the management of individual hypertensive patients as it may provide useful information concerning the potential severity of coronary vascular dysfunction. 


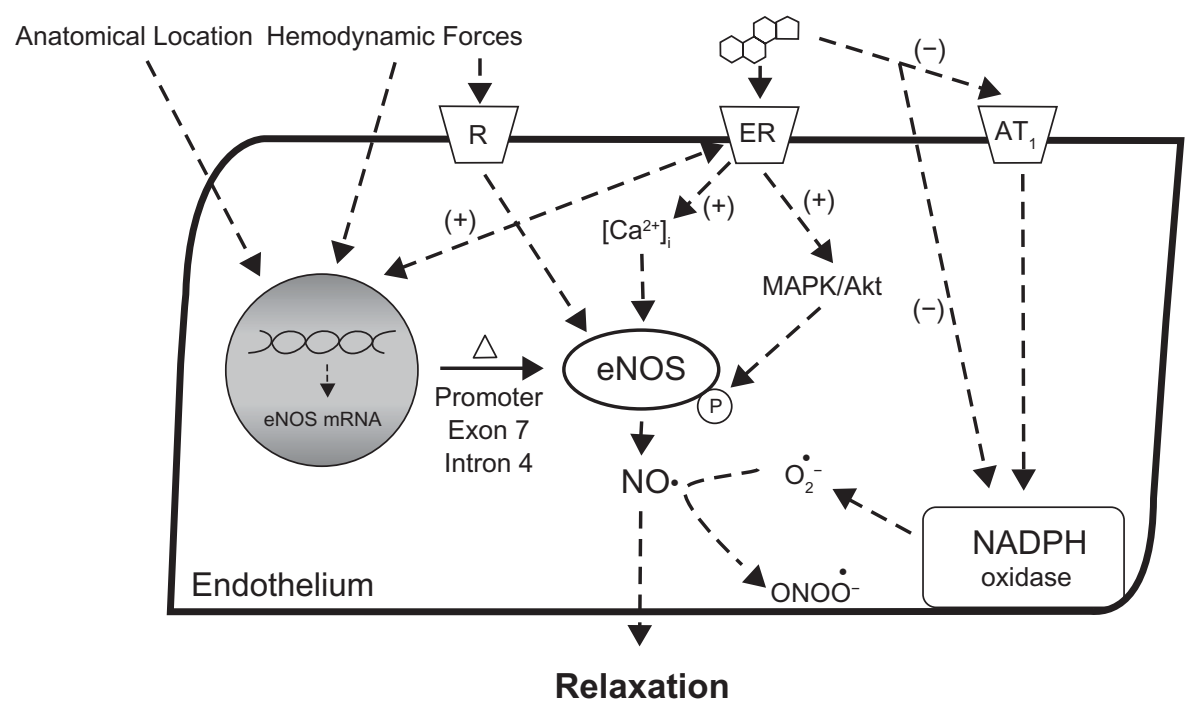

Figure 2 Effects of genetic factors and estrogen on eNOS function and NO bioavailability in coronary arteries with hypertension. Activation of the membrane-bound estrogen receptor can increase eNOS expression and activation as well as reduce the destruction of NO by superoxide, thereby increasing NO available for relaxation. Local hemodynamics, location in the coronary vascular bed, and genetic polymorphisms can also affect eNOS expression and may impact coronary relaxation in hypertension. Abbreviations: R, receptor; ER, estrogen receptor; ATI, type I angiotension II receptor; NO, nitric oxide; O2*-, superoxide; ONOO-, peroxynitrite; MAPK, mitogen-activated protein kinase; Akt, protein kinase B.

\section{Heterogeneity of eNOS expression in the coronary vascular bed}

As might be expected from the known dependency of vasomotor control mechanisms on the position of a given vessel type in the vascular tree, $, 5,5$ the distribution of the eNOS protein is likewise not uniform throughout the coronary vasculature of normal healthy hearts. Laughlin and colleagues demonstrated a reduced eNOS protein content per $\mathrm{mg}$ total vessel protein in the smallest porcine coronary resistance arteries $(\leq 50 \mu \mathrm{M})$ compared to larger coronary arteries, despite a large reduction in the smooth muscle cell-to-endothelial cell ratio as coronary artery diameter decreases. ${ }^{104}$ These data suggest that the largest coronary conduit vessels have a very large expression of eNOS protein in each endothelial cell. The authors postulate that the greater eNOS content in conduit arteries may be necessary to provide adequate NO for dilation of multiple layers of vascular smooth muscle, or may provide NO for dilation of downstream vessels. ${ }^{104}$ The reported expression pattern for eNOS is consistent with a greater dependence on NO-mediated, endothelium-dependent dilation in larger arteries compared to the smallest arterioles. ${ }^{2,5,6}$

The coronary artery is characterized by asynchronous hemodynamics, wherein the wall shear stress from blood flow is out of phase with the circumferential strain from blood pressure $^{105}$ and this may play a role in determining the heterogeneous eNOS expression in the coronary arterial tree. ${ }^{106,107}$ Further support for the role of hemodynamics in eNOS protein expression comes from studies in miniature swine following prolonged aerobic exercise training. ${ }^{108}$ Following weeks of training, eNOS protein content was increased by over $50 \%$ in coronary arteries and small and large arterioles, but unaltered in coronary conduit and intermediate arterioles, ${ }^{108}$ suggesting that steady state adaptations to exercise hemodynamic stimuli include nonuniform changes in eNOS expression that lead to an NO-mediated improvement in coronary resistance artery endothelium-dependent dilation. ${ }^{109}$

Thus, eNOS protein expression is nonuniformly distributed throughout the coronary vasculature, possibly as the result of local hemodynamic influences, and eNOS expression may be altered in response to changes in coronary hemodynamics caused by exercise (Figure 2). The hemodynamics of the coronary circulation are altered in hypertension ${ }^{9,59}$ and likely affect the distribution of eNOS expression throughout the coronary vasculature. Whether the heterogeneous distribution of eNOS and NO-mediated vasomotor activity in the coronary vasculature may be altered by hypertension, and the mechanisms responsible have not been directly tested. If so, there may be implications for the loci of $\mathrm{NO}$ dependent events such as blood flow control, thrombosis, adhesion and cellular infiltration, and VSM hypertrophy and proliferation.

\section{Sex-dependent function of the coronary vasculature and the role of estrogen}

It is widely recognized that young adult females compared to males or postmenopausal females have a lower incidence 
of morbidity and mortality from coronary artery disease. ${ }^{110}$ It is likely that sex-dependent differences in vascular endothelial function contribute to this phenomenon. Direct studies of coronary vascular endothelium function have demonstrated greater maximal relaxations and sensitivity to endotheliumdependent agonists in isolated coronary arteries from healthy female compared to male pigs. ${ }^{111}$ Furthermore, increases in intravascular pressure elicited smaller myogenic constrictions in isolated rat coronary arteries from females compared to males, and the larger diameters of the female coronary arteries were associated with higher endothelial $\mathrm{Ca}^{2+}$ concentrations and eNOS activity. ${ }^{112}$ Elevated NO release from female compared to male coronary arteries has been observed in a number of studies, ${ }^{113-115}$ and is consistent with findings in a variety of other artery types.

There is also a consistent sex-dependent effect in the endothelium-dependent NO-mediated vasorelaxation in hypertensive rats. Thus, although both male and female SHR have lower endothelium-dependent relaxation responses in isolated aortas compared to their respective normotensive WKY counterparts, ACh elicited greater relaxations in female than in male SHR aorta. ${ }^{116,117}$ Furthermore, whereas high ACh concentrations result in re-contractions of isolated aortic segments from male SHR, this response did not occur in aortas of female SHR. ${ }^{116,117}$ This general response was also observed in isolated aortas of stroke-prone SHR. ${ }^{118}$ These sex-dependent functional effects have not been studied in the coronary circulation of hypertensive animals. It would be valuable to systematically assess this and to determine the mechanisms accounting for sex-differences in the coronary vascular function in order to better understand the molecular and functional basis for sex differences in vascular disease, and to provide foundation for possible sex-dependent diagnostic and treatment strategies.

It is possible that estrogen-independent mechanisms contribute to sex differences in endothelium-dependent vasomotor function and eNOS expression and activity, but there is general consensus that estrogen is a major signal coordinating the sex-dependent vascular function and phenotype (Figure 2). ${ }^{119-121}$ Estrogen treatment has been demonstrated to enhance coronary blood flow, ${ }^{122-125}$ endothelial eNOS expression and activity levels, ${ }^{126-129}$ and NO release. ${ }^{14,125,130,131}$ Estrogen's effect on endothelium NO-mediated action may occur by endothelium dependent genomic, nongenomic, and antioxidant mechanisms in the coronary vasculature. Although these specific mechanisms have not been examined extensively in hypertension models, the following sections briefly outline evidence for these mechanisms affecting the coronary vascular bed, and are intended to provide provocation for further study in the context of sex-dependent coronary vascular phenotypes in hypertension.

\section{Endothelium-dependent genomic action of estrogen in the coronary vasculature}

Activation of estrogen receptors (ER) mediates the upregulation of $\operatorname{eNOS}^{128,132}$ via a specific estrogen response element in the eNOS gene promoter region (Figure 2). ${ }^{133}$ Muller-Delp and colleagues demonstrated that estrogen treatment increased eNOS protein in coronary arteries of ovariectomized ER $\mathrm{E}_{\alpha}$ deficient mice. ${ }^{134}$ However, eNOS levels were not restored to those seen in estrogen-treated ovariectomized wild-type mice, suggesting partial control through $\mathrm{ER}_{\alpha}$ and $\mathrm{ER}_{\beta}$. In human coronary artery endothelial cells, 17 $\beta$-estradiol treatment resulted in significantly increased eNOS protein levels and attendant elevations in basal and A23187-induced NO release, ${ }^{135}$ effects which were completely inhibited in the presence of ICI182,780, a specific estrogen-receptor antagonist. Collectively, these and other studies indicate that genomic effects of estrogen on eNOS expression could influence coronary vascular function and account for sexdifferences. Application of this knowledge to studies of the coronary vascular bed of hypertensive individuals should be undertaken to assess whether these effects occur or are disrupted in hypertension and when estrogen status changes in hypertensive individuals.

\section{Endothelium-dependent nongenomic action of estrogen in the coronary vasculature}

At physiological concentrations, estrogen can modulate vascular tone by inducing rapid release of NO from the endothelium that is not dependent on eNOS transcription (Figure 2). For instance, 15 min of intracoronary $17 \beta$-estradiol infusion potentiated coronary microvascular vasodilator responses to $\mathrm{ACh}$ in postmenopausal women in an endotheliumdependent manner. ${ }^{136}$ Animal models support this nongenomic activation of eNOS potentiating endothelium-dependent vasodilation. ${ }^{126,129}$ Although enhanced basal NO levels in the female coronary vasculature have been attributed to sex differences in $\mathrm{Ca}^{2+}$-handling mechanisms of the vascular endothelium, ${ }^{112}$ the stimulation of NO production during estrogen administration has also been reported to occur independently of $\mathrm{Ca}^{2+}$ mobilization. ${ }^{137}$ This mechanism likely involves a functional signaling unit localized in the endothelial plasmalemmal caveolae where ERs and eNOS are found. ${ }^{138}$ 
Estrogen binding thus leads to eNOS phosphorylation via ERK $_{1 / 2}$ and PI3-kinase/Akt-dependent pathways. Rapid release of NO occurs once eNOS has dissociated from caveolin-1 and united with the scaffolding protein Hsp90. ${ }^{137}$ Regardless of the particular cell signaling mechanisms involved, these preliminary findings suggest an acute sensitivity to changes in estrogen that may have functional impact in the coronary circulation. It could be important to know whether this plays a role in heterogeneity between sexes and within females with different estrogen status, with respect to the overall control of the coronary vascular bed in hypertension as this could affect prevention, diagnosis and treatment decisions.

\section{Antioxidant effects of estrogen on the coronary vasculature}

The specific mechanisms of estrogen's antioxidant effect are likely manifold and likely involve both genomic and nongenomic motifs. ${ }^{133}$ One intriguing possibility related to vascular adaptations in hypertension involves potential effects of estrogen on AII-induced NAD $(\mathrm{P}) \mathrm{H}$ oxidase activity. ${ }^{139}$ Pretreatment of bovine coronary microvascular endothelial cells with $17 \beta$-estradiol prevented increases in NAD(P)H oxidase expression observed after 24 hours of AII stimulation alone. Inhibition of ERs by ICI182,780 did not alter the estradiol-induced decrease in AII-stimulated $\mathrm{NAD}(\mathrm{P}) \mathrm{H}$ expression, suggesting that the effect of estrogen was not ER-mediated. ${ }^{139}$ However, estrogen administration did prevent AII-induced increases in type 1 angiotensin II receptors $\left(\mathrm{AT}_{1}\right) .{ }^{139}$ It has been proposed that estrogen's antioxidant effects may be mediated via this down-regulation of $\mathrm{AT}_{1}$ receptors, causing decreased superoxide anion production and improved NO bioavailability. This estrogen signaling may occur via non-ER-dependent modulation of either the endothelial membrane properties, or via chemical antioxidant properties of estrogen itself. ${ }^{140}$ Regardless of the specific mechanism linking estrogen to $\mathrm{NAD}(\mathrm{P}) \mathrm{H}$ oxidase expression in coronary vascular endothelium, these observations seem to be of great importance in the context of hypertension, as upregulation of vascular cell $\mathrm{NAD}(\mathrm{P}) \mathrm{H}$ oxidase is the major source of elevated vascular ROS which are thought to make a large contribution to the endothelial dysfunction accompanying hypertension. ${ }^{48,72}$ Thus, this mechanism should be of interest in examining potential sex-dependent coronary vascular adaptations in hypertension.

\section{Summary}

Many specific details regarding the regulation of NO bioavailability in the coronary vascular bed in hypertension are still unclear. Compensations, both from non-NO endothelium-derived vasodilators, and possibly by other isoforms of NOS occur when eNOS functionality is impaired. There is some evidence that similar compensations may occur in hypertension, but much more research is required to define mechanisms of the compensatory changes and to describe the signals associated with hypertension that trigger these changes. Polymorphisms of eNOS have been associated with hypertension incidence, and some emerging data suggest that coronary vascular function is also associated with certain eNOS polymorhisms; although these are promising findings, again the mechanistic details linking eNOS polymorphisms with coronary vascular function in hypertension remain to be rigorously established. Changes in endothelium-dependent function contribute to sex differences in cardiovascular disease. It has been demonstrated that estrogen has several mechanisms of action that improve NO bioavailability, including some known to be altered in hypertension.

Based on known functional effects of the identified factors that regulate coronary vascular NO mechanisms, it is intriguing to speculate that these will also be important mechanisms in the coronary vascular adaptations to hypertension. Basic information concerning compensatory vasodilator pathways, NOS isoform shifts, eNOS polymorphisms and sex- and estrogen status-dependent effects on NO bioavailability may be very helpful in designing more effective prevention, diagnostic and therapeutic strategies to deal with coronary vascular dysfunction in hypertension and cardiovascular disease.

\section{Acknowledgments}

Related work in the authors' laboratory is funded by the Natural Sciences and Engineering Research Council of Canada (NSERC) and the Heart and Stroke Foundation of Ontario. JT Kroetsch, AS Levy, and JCS Chung were supported by Canada Graduate Scholarships from NSERC. JWE Rush is Canada Research Chair in Integrative Vascular Biology. The authors report no conflicts of interest in this work.

\section{References}

1. Feigl EO. Coronary physiology. Physiol Rev. 1983;63:1-205.

2. Muller JM, Davis MJ, Chilian WM. Integrated regulation of pressure and flow in the coronary microcirculation. Cardiovasc Res. 1996;32:668-678.

3. Tune JD, Gorman MW, Feigl EO. Matching coronary blood flow to myocardial oxygen consumption. J Appl Physiol. 2004;97:404-415.

4. Westerhof N, Boer C, Lamberts RR, Sipkema P. Cross-talk between cardiac muscle and coronary vasculature. Physiol Rev. 2006;86: 1263-1308. 
5. Jones CJ, Kuo L, Davis MJ, Chilian WM. Regulation of coronary blood flow: coordination of heterogeneous control mechanisms in vascular microdomains. Cardiovasc Res. 1995;29:585-596.

6. Feliciano L, Henning RJ. Coronary artery blood flow: physiologic and pathophysiologic regulation. Clin Cardiol. 1999;22:775-786.

7. Chilian WM, Eastham CL, Marcus ML. Microvascular distribution of coronary vascular resistance in beating left ventricle. Am J Physiol. 1986;251:H779-H788.

8. Chilian WM. Microvascular pressures and resistances in the left ventricular subepicardium and subendocardium. Circ Res. 1991;69: 561-570.

9. Nitenberg A, Antony I. Epicardial coronary arteries are not adequately sized in hypertensive patients. J Am Coll Cardiol. 1996;27:115-123.

10. Antony I, Nitenberg A. Coronary vascular reserve is similarly reduced in hypertensive patients without any other coronary risk factors and in normotensive smokers and hypercholesterolemic patients with angiographically normal coronary arteries. Am J Hypertens. 1997;10: 181-188.

11. Kozakova M, Galetta F, Gregorini L, et al. Coronary vasodilator capacity and epicardial vessel remodeling in physiological and hypertensive hypertrophy. Hypertension. 2000;36:343-349.

12. Palombo C, Kozakova M, Magagna A, et al. Early impairment of coronary flow reserve and increase in minimum coronary resistance in borderline hypertensive patients. J Hypertens. 2000;18:453-459.

13. Wangler RD, Peters KG, Marcus ML, Tomanek RJ. Effects of duration and severity of arterial hypertension and cardiac hypertrophy on coronary vasodilator reserve. Circ Res. 1982;51:10-18.

14. Edoute Y, Luscher TF, Rubanyi GM. Autoregulation and vascular reserve in the coronary circulation of the spontaneously hypertensive rat. J Hypertens Suppl. 1986;4:S290-S292.

15. Friberg P, Wahlander H, Nordlander M. Structural and functional adaptations within the myocardium and coronary vessels after antihypertensive therapy in spontaneously hypertensive rats. J Hypertens Suppl. 1986;4: S519-S521.

16. Isoyama S, Sato F, Takishima T. Effect of age on coronary circulation after imposition of pressure-overload in rats. Hypertension. 1991;17: 369-377.

17. Fujita H, Takeda K, Nakamura K, et al. Role of nitric oxide in impaired coronary circulation and improvement by angiotensin II receptor antagonist in spontaneously hypertensive rats. Clin Exp Pharmacol Physiol Suppl. 1995;22:S148-S150.

18. Kelm M, Feelisch M, Krebber T, Deussen A, Motz W, Strauer BE. Role of nitric oxide in the regulation of coronary vascular tone in hearts from hypertensive rats. Maintenance of nitric oxide-forming capacity and increased basal production of nitric oxide. Hypertension. 1995;25:186-193.

19. Crabos M, Coste P, Paccalin M, et al. Reduced basal NO-mediated dilation and decreased endothelial NO-synthase expression in coronary vessels of spontaneously hypertensive rats. J Mol Cell Cardiol. 1997;29:55-65.

20. Susic D, Nunez E, Hosoya K, Frohlich ED. Coronary hemodynamics in aging spontaneously hypertensive and normotensive Wistar-Kyoto rats. J Hypertens. 1998;16:231-237.

21. Millette E, de CJ, Lamontagne D. Altered coronary dilation in deoxycorticosterone acetate-salt hypertension. J Hypertens. 2000;18: 1783-1793.

22. Mokuno S, Ito T, Numaguchi $Y$, et al. Impaired nitric oxide production and enhanced autoregulation of coronary circulation in young spontaneously hypertensive rats at prehypertensive stage. Hypertens Res. 2001;24:395-401.

23. Trippodo NC, Frohlich ED. Similarities of genetic (spontaneous) hypertension. Man and rat. Circ Res. 1981;48:309-319.

24. Bohr DF, Dominiczak AF. Experimental hypertension. Hypertension. 1991;17:I39-I44.

25. Yamori Y. Overview: studies on spontaneous hypertension-development from animal models toward man. Clin Exp Hypertens A. 1991;13: 631-644.
26. Pinto YM, Paul M, Ganten D. Lessons from rat models of hypertension: from Goldblatt to genetic engineering. Cardiovasc Res. 1998;39:77-88.

27. Yagil Y, Yagil C. Genetic models of hypertension in experimental animals. Exp Nephrol. 2001;9:1-9.

28. Lerman LO, Chade AR, Sica V, Napoli C. Animal models of hypertension: an overview. J Lab Clin Med. 2005;146:160-173.

29. Hutchins PM, Lynch CD, Cooney PT, Curseen KA. The microcirculation in experimental hypertension and aging. Cardiovasc Res. 1996;32:772-780.

30. Greene AS. Microvascular regulation and dysregulation. In: Izzo JL Jr, Black HR, editors. Hypertension Primer: The essentials of high blood pressure. 3rd ed. Philidelphia, PA: Lippincott Williams \& Wilkins; 2003. p. 183-185.

31. Garcia SR, Izzard AS, Heagerty AM, Bund SJ. Myogenic tone in coronary arteries from spontaneously hypertensive rats. $J$ Vasc Res. 1997;34:109-116.

32. Ghaleh B, Hittinger L, Kim SJ, et al. Selective large coronary endothelial dysfunction in conscious dogs with chronic coronary pressure overload. Am J Physiol. 1998;274:H539-H551.

33. Bund SJ. Influence of mode of contraction on the mechanism of acetylcholine-mediated relaxation of coronary arteries from normotensive and spontaneously hypertensive rats. Clin Sci (Lond). 1998;94: 231-238.

34. Baumbach GL, Heistad DD. Remodeling of cerebral arterioles in chronic hypertension. Hypertension. 1989;13:968-972.

35. Baumbach GL. Mechanisms of vascular remodeling. In: Izzo JL Jr, Black HR, editors. Hypertension Primer: The essentials of high blood pressure. 3rd ed. Philadelphia, PA: Lippincott Williams \& Wilkins; 2003. p. $180-183$.

36. Millette E, Demeilliers B, Wu R, et al. Comparison of the cardiovascular protection by omapatrilat and lisinopril treatments in DOCA-salt hypertension. J Hypertens. 2003;21:125-135.

37. Vanhoutte PM, Feletou M, Taddei S. Endothelium-dependent contractions in hypertension. Br J Pharmacol. 2005;144:449-458.

38. Feletou M, Vanhoutte PM. Endothelial dysfunction: a multifaceted disorder(The Wiggers Award Lecture). Am J Physiol Heart Circ Physiol. 2006;291:H985-H1002.

39. Liu Y, Gutterman DD. Vascular control in humans: focus on the coronary microcirculation. Basic Res Cardiol. 2009;104:211-227.

40. Godecke A, Decking UK, Ding Z, et al. Coronary hemodynamics in endothelial NO synthase knockout mice. Circ Res. 1998;82:186-194.

41. Miura H, Liu Y, Gutterman DD. Human coronary arteriolar dilation to bradykinin depends on membrane hyperpolarization: contribution of nitric oxide and $\mathrm{Ca}^{2+}$-activated $\mathrm{K}^{+}$channels. Circulation. 1999;99: $3132-3138$

42. Godecke A, Schrader J. Adaptive mechanisms of the cardiovascular system in transgenic mice--lessons from eNOS and myoglobin knockout mice. Basic Res Cardiol. 2000;95:492-498.

43. Miura H, Wachtel RE, Liu Y, et al. Flow-induced dilation of human coronary arterioles: important role of $\mathrm{Ca}^{2+}$-activated $\mathrm{K}^{+}$channels. Circulation. 2001;103:1992-1998.

44. Ding Z, Godecke A, Schrader J. Contribution of cytochrome P450 metabolites to bradykinin-induced vasodilation in endothelial NO synthase deficient mouse hearts. Br J Pharmacol. 2002;135:631-638.

45. Aubin MC, Gendron ME, Lebel V, et al. Alterations in the endothelial G-protein coupled receptor pathway in epicardial arteries and subendocardial arterioles in compensated left ventricular hypertrophy. Basic Res Cardiol. 2007;102:144-153.

46. Heintz A, Damm M, Brand M, Koch T, Deussen A. Coronary flow regulation in mouse heart during hypercapnic acidosis: role of $\mathrm{NO}$ and its compensation during eNOS impairment. Cardiovasc Res. 2008; 77:188-196.

47. Cai H, Harrison DG. Endothelial dysfunction in cardiovascular diseases: the role of oxidant stress. Circ Res. 2000;87:840-844.

48. Rush JW, Denniss SG, Graham DA. Vascular nitric oxide and oxidative stress: determinants of endothelial adaptations to cardiovascular disease and to physical activity. Can J Appl Physiol. 2005;30:442-474. 
49. Kelm M, Schrader J. Control of coronary vascular tone by nitric oxide. Circ Res. 1990;66:1561-1575.

50. Tschudi MR, Noll G, Arnet U, Novosel D, Ganten D, Luscher TF. Alterations in coronary artery vascular reactivity of hypertensive Ren-2 transgenic rats. Circulation. 1994;89:2780-2786.

51. Bouloumie A, Bauersachs J, Linz W, et al. Endothelial dysfunction coincides with an enhanced nitric oxide synthase expression and superoxide anion production. Hypertension. 1997;30:934-941.

52. Bauersachs J, Bouloumie A, Mulsch A, Wiemer G, Fleming I, Busse R. Vasodilator dysfunction in aged spontaneously hypertensive rats: changes in NO synthase III and soluble guanylyl cyclase expression, and in superoxide anion production. Cardiovasc Res. 1998;37: 772-779.

53. Brush JE Jr, Faxon DP, Salmon S, Jacobs AK, Ryan TJ. Abnormal endothelium-dependent coronary vasomotion in hypertensive patients. J Am Coll Cardiol. 1992;19:809-815.

54. Treasure CB, Manoukian SV, Klein JL, et al. Epicardial coronary artery responses to acetylcholine are impaired in hypertensive patients. Circ Res. 1992;71:776-781.

55. Treasure CB, Klein JL, Vita JA, et al. Hypertension and left ventricular hypertrophy are associated with impaired endothelium-mediated relaxation in human coronary resistance vessels. Circulation. 1993; 87:86-93.

56. Quyyumi AA, Dakak N, Andrews NP, et al. Nitric oxide activity in the human coronary circulation. Impact of risk factors for coronary atherosclerosis. J Clin Invest. 1995;95:1747-1755.

57. Houghton JL, Davison CA, Kuhner PA, Torossov MT, Strogatz DS, Carr AA. Heterogeneous vasomotor responses of coronary conduit and resistance vessels in hypertension. J Am Coll Cardiol. 1998;31: 374-382.

58. Pourageaud F, Freslon JL. Endothelial and smooth muscle properties of coronary and mesenteric resistance arteries in spontaneously hypertensive rats compared to WKY rats. Fundam Clin Pharmacol. 1995;9:37-45.

59. Pourageaud F, Freslon JL. Impaired endothelial relaxations induced by agonists and flow in spontaneously hypertensive rat compared to Wistar-Kyoto rat perfused coronary arteries. J Vasc Res. 1995;32: 190-199.

60. MacCarthy PA, Shah AM. Impaired endothelium-dependent regulation of ventricular relaxation in pressure-overload cardiac hypertrophy. Circulation. 2000;101:1854-1860.

61. Malo O, Carrier M, Shi YF, Tardif JC, Tanguay JF, Perrault LP. Specific alterations of endothelial signal transduction pathways of porcine epicardial coronary arteries in left ventricular hypertrophy. J Cardiovasc Pharmacol. 2003;42:275-286.

62. Demirci B, McKeown PP, Bayraktutan U. Blockade of angiotensin II provides additional benefits in hypertension- and ageing-related cardiac and vascular dysfunctions beyond its blood pressure-lowering effects J Hypertens. 2005;23:2219-2227.

63. Tschudi MR, Criscione L, Luscher TF. Effect of aging and hypertension on endothelial function of rat coronary arteries. J Hypertens Suppl. 1991;9:S164-S165.

64. Gauthier-Rein KM, Rusch NJ. Distinct endothelial impairment in coronary microvessels from hypertensive Dahl rats. Hypertension. 1998;31:328-334.

65. Fuchs LC, Nuno D, Lamping KG, Johnson AK. Characterization of endothelium-dependent vasodilation and vasoconstriction in coronary arteries from spontaneously hypertensive rats. Am J Hypertens. 1996;9:475-483.

66. Kelm M, Feelisch M, Krebber T, Motz W, Strauer BE. The role of nitric oxide in the regulation of coronary vascular resistance in arterial hypertension: comparison of normotensive and spontaneously hypertensive rats. J Cardiovasc Pharmacol. 1992;20 Suppl 12:S183-S186.

67. Duffy SJ, Castle SF, Harper RW, Meredith IT. Contribution of vasodilator prostanoids and nitric oxide to resting flow, metabolic vasodilation, and flow-mediated dilation in human coronary circulation. Circulation. 1999;100:1951-1957.
68. Tschudi MR, Criscione L, Novosel D, Pfeiffer K, Luscher TF. Antihypertensive therapy augments endothelium-dependent relaxations in coronary arteries of spontaneously hypertensive rats. Circulation. 1994;89:2212-2218.

69. Vazquez-Perez S, Navarro-Cid J, de las HN, et al. Relevance of endothelium-derived hyperpolarizing factor in the effects of hypertension on rat coronary relaxations. J Hypertens. 2001;19:539-545.

70. Garcia SR, Bund SJ. Nitric oxide modulation of coronary artery myogenic tone in spontaneously hypertensive and Wistar-Kyoto rats. Clin Sci (Lond). 1998;94:225-229.

71. Zhang C, Hein TW, Wang W, et al. Upregulation of vascular arginase in hypertension decreases nitric oxide-mediated dilation of coronary arterioles. Hypertension. 2004;44:935-943.

72. Rush JW, Ford RJ. Nitric oxide, oxidative stress and vascular endothelium in health and hypertension. Clin Hemorheol Microcirc. 2007;37: 185-192.

73. Rodriguez-Porcel M, Lerman LO, Herrmann J, Sawamura T, Napoli C, Lerman A. Hypercholesterolemia and hypertension have synergistic deleterious effects on coronary endothelial function. Arterioscler Thromb Vasc Biol. 2003;23:885-891.

74. Zhu XY, Daghini E, Chade AR, et al. Role of oxidative stress in remodeling of the myocardial microcirculation in hypertension. Arterioscler Thromb Vasc Biol. 2006;26:1746-1752.

75. Lu Z, Xu X, Hu X, et al. Extracellular superoxide dismutase deficiency exacerbates pressure overload-induced left ventricular hypertrophy and dysfunction. Hypertension. 2008;51:19-25.

76. Lee MY, Griendling KK. Redox signaling, vascular function, and hypertension. Antioxid Redox Signal. 2008;10:1045-1059.

77. Munzel T, Daiber A, Ullrich V, Mulsch A. Vascular consequences of endothelial nitric oxide synthase uncoupling for the activity and expression of the soluble guanylyl cyclase and the cGMP-dependent protein kinase. Arterioscler Thromb Vasc Biol. 2005;25:1551-1557.

78. Thomas SR, Witting PK, Drummond GR. Redox control of endothelial function and dysfunction: molecular mechanisms and therapeutic opportunities. Antioxid Redox Signal. 2008;10:1713-1765.

79. Huang PL, Huang Z, Mashimo H, et al. Hypertension in mice lacking the gene for endothelial nitric oxide synthase. Nature. 1995;377:239-242.

80. Kubis N, Besnard S, Silvestre JS, et al. Decreased arteriolar density in endothelial nitric oxide synthase knockout mice is due to hypertension, not to the constitutive defect in endothelial nitric oxide synthase enzyme. J Hypertens. 2002;20:273-280.

81. Kubis N, Richer C, Domergue V, Giudicelli JF, Levy BI. Role of microvascular rarefaction in the increased arterial pressure in mice lacking for the endothelial nitric oxide synthase gene $\left(\mathrm{eNOS} \mathrm{pt}^{--}\right)$. J Hypertens. 2002;20:1581-1587.

82. Chataigneau T, Feletou M, Huang PL, Fishman MC, Duhault J, Vanhoutte PM. Acetylcholine-induced relaxation in blood vessels from endothelial nitric oxide synthase knockout mice. BrJ Pharmacol. 1999;126:219-226.

83. Lamping KG, Nuno DW, Shesely EG, Maeda N, Faraci FM. Vasodilator mechanisms in the coronary circulation of endothelial nitric oxide synthase-deficient mice. Am J Physiol Heart Circ Physiol. 2000;279: H1906-H1912.

84. Michel T, Feron O. Nitric oxide synthases: which, where, how, and why? J Clin Invest. 1997;100:2146-2152.

85. Nava E, Noll G, Luscher TF. Increased activity of constitutive nitric oxide synthase in cardiac endothelium in spontaneous hypertension. Circulation. 1995;91:2310-2313.

86. Piech A, Massart PE, Dessy C, et al. Decreased expression of myocardial eNOS and caveolin in dogs with hypertrophic cardiomyopathy. Am J Physiol Heart Circ Physiol. 2002;282:H219-H231.

87. Ravalli S, Albala A, Ming M, et al. Inducible nitric oxide synthase expression in smooth muscle cells and macrophages of human transplant coronary artery disease. Circulation. 1998;97:2338-2345.

88. Vaziri ND, Ni Z, Oveisi F, Trnavsky-Hobbs DL. Effect of antioxidant therapy on blood pressure and NO synthase expression in hypertensive rats. Hypertension. 2000;36:957-964. 
89. Huang A, Sun D, Shesely EG, Levee EM, Koller A, Kaley G. Neuronal NOS-dependent dilation to flow in coronary arteries of male eNOS-KO mice. Am J Physiol Heart Circ Physiol. 2002;282:H429-H436.

90. Ungvari Z, Csiszar A, Edwards JG, et al. Increased superoxide production in coronary arteries in hyperhomocysteinemia: role of tumor necrosis factor-alpha, $\mathrm{NAD}(\mathrm{P}) \mathrm{H}$ oxidase, and inducible nitric oxide synthase. Arterioscler Thromb Vasc Biol. 2003;23:418-424.

91. Graham DA, Rush JW. Exercise training improves aortic endotheliumdependent vasorelaxation and determinants of nitric oxide bioavailability in spontaneously hypertensive rats. $J$ Appl Physiol. 2004;96: 2088-2096.

92. Li H, Witte K, August M, et al. Reversal of endothelial nitric oxide synthase uncoupling and up-regulation of endothelial nitric oxide synthase expression lowers blood pressure in hypertensive rats. $J \mathrm{Am}$ Coll Cardiol. 2006;47:2536-2544.

93. Schulz E, Jansen T, Wenzel P, Daiber A, Munzel T. Nitric oxide, tetrahydrobiopterin, oxidative stress, and endothelial dysfunction in hypertension. Antioxid Redox Signal. 2008;10:1115-1126.

94. Malo O, Desjardins F, Tanguay JF, Tardif JC, Carrier M, Perrault LP. Tetrahydrobiopterin and antioxidants reverse the coronary endothelial dysfunction associated with left ventricular hypertrophy in a porcine model. Cardiovasc Res. 2003;59:501-511.

95. Khadour FH, Kao RH, Park S, Armstrong PW, Holycross BJ, Schulz R. Age-dependent augmentation of cardiac endothelial NOS in a genetic rat model of heart failure. Am J Physiol. 1997;273: H1223-H1230.

96. Miyamoto Y, Saito Y, Kajiyama N, et al. Endothelial nitric oxide synthase gene is positively associated with essential hypertension. Hypertension. 1998;32:3-8.

97. Wang XL, Wang J. Endothelial nitric oxide synthase gene sequence variations and vascular disease. Mol Genet Metab. 2000;70:241-251.

98. Sandrim VC, de Syllos RW, Lisboa HR, Tres GS, Tanus-Santos JE. Endothelial nitric oxide synthase haplotypes affect the susceptibility to hypertension in patients with type 2 diabetes mellitus. Atherosclerosis. 2006;189:241-246.

99. Sandrim VC, de Syllos RW, Lisboa HR, Tres GS, Tanus-Santos JE. Influence of eNOS haplotypes on the plasma nitric oxide products concentrations in hypertensive and type 2 diabetes mellitus patients. Nitric Oxide. 2007;16:348-355.

100. Nakayama M, Yasue H, Yoshimura M, et al. T-786 - >C mutation in the 5'-flanking region of the endothelial nitric oxide synthase gene is associated with coronary spasm. Circulation. 1999;99:2864-2870.

101. Wang J, Dudley D, Wang XL. Haplotype-specific effects on endothelial NO synthase promoter efficiency: modifiable by cigarette smoking. Arterioscler Thromb Vasc Biol. 2002;22:e1-e4.

102. Naber CK, Baumgart D, Altmann C, Siffert W, Erbel R, Heusch G. eNOS 894T allele and coronary blood flow at rest and during adenosine-induced hyperemia. Am J Physiol Heart Circ Physiol. 2001;281: H1908-H1912.

103. Kunnas TA, Lehtimaki T, Laaksonen R, et al. Endothelial nitric oxide synthase genotype modulates the improvement of coronary blood flow by pravastatin: a placebo-controlled PET study. J Mol Med. 2002;80:802-807.

104. Laughlin MH, Turk JR, Schrage WG, Woodman CR, Price EM. Influence of coronary artery diameter on eNOS protein content. Am J Physiol Heart Circ Physiol. 2003;284:H1307-H1312.

105. Qiu Y, Tarbell JM. Numerical simulation of pulsatile flow in a compliant curved tube model of a coronary artery. J Biomech Eng. 2000;122:77-85.

106. Dancu MB, Berardi DE, Vanden Heuvel JP, Tarbell JM. Asynchronous shear stress and circumferential strain reduces endothelial NO synthase and cyclooxygenase-2 but induces endothelin-1 gene expression in endothelial cells. Arterioscler Thromb Vasc Biol. 2004;24:2088-2094.

107. Dancu MB, Tarbell JM. Coronary endothelium expresses a pathologic gene pattern compared to aortic endothelium: correlation of asynchronous hemodynamics and pathology in vivo. Atherosclerosis. 2007;192:9-14.
108. Laughlin MH, Pollock JS, Amann JF, Hollis ML, Woodman CR, Price EM. Training induces nonuniform increases in eNOS content along the coronary arterial tree. $J$ Appl Physiol. 2001;90:501-510.

109. Muller JM, Myers PR, Laughlin MH. Vasodilator responses of coronary resistance arteries of exercise-trained pigs. Circulation. 1994;89:2308-2314.

110. Nathan L, Chaudhuri G. Estrogens and atherosclerosis. Annu Rev Pharmacol Toxicol. 1997;37:477-515.

111. Barber DA, Miller VM. Gender differences in endothelium-dependent relaxations do not involve $\mathrm{NO}$ in porcine coronary arteries. $\mathrm{Am} J$ Physiol. 1997;273:H2325-H2332.

112. Knot HJ, Lounsbury KM, Brayden JE, Nelson MT. Gender differences in coronary artery diameter reflect changes in both endothelial $\mathrm{Ca}^{2+}$ and ecNOS activity. Am J Physiol. 1999;276:H961-H969.

113. Wellman GC, Bonev AD, Nelson MT, Brayden JE. Gender differences in coronary artery diameter involve estrogen, nitric oxide, and $\mathrm{Ca}^{2+}$-dependent $\mathrm{K}^{+}$channels. Circ Res. 1996;79:1024-1030.

114. Darkow DJ, Lu L, White RE. Estrogen relaxation of coronary artery smooth muscle is mediated by nitric oxide and cGMP. Am J Physiol. 1997;272:H2765-H2773.

115. Ma L, Robinson CP, Thadani U, Patterson E. Effect of 17-beta estradiol in the rabbit: endothelium-dependent and -independent mechanisms of vascular relaxation. J Cardiovasc Pharmacol. 1997;30:130-135.

116. Kauser K, Rubanyi GM. Gender difference in endothelial dysfunction in the aorta of spontaneously hypertensive rats. Hypertension. 1995;25:517-523.

117. Graham DA, Rush JWE. Cyclooxygenase and thromboxane/ prostaglandin receptor contribute to aortic endothelium-dependent dysfunction in aging female spontaneously hypertensive rats. $J \mathrm{Appl}$ Physiol. 2009;107:1059-1067.

118. McIntyre M, Hamilton CA, Rees DD, Reid JL, Dominiczak AF. Sex differences in the abundance of endothelial nitric oxide in a model of genetic hypertension. Hypertension. 1997;30:1517-1524.

119. Pinto S, Virdis A, Ghiadoni L, et al. Endogenous estrogen and acetylcholine-induced vasodilation in normotensive women. Hypertension. 1997;29:268-273.

120. Lima SM, Aldrighi JM, Consolim-Colombo FM, et al. Acute administration of 17beta-estradiol improves endothelium-dependent vasodilation in postmenopausal women. Maturitas. 2005;50:266-274.

121. New G, Duffy SJ, Harper RW, Meredith IT. Estrogen improves acetylcholine-induced but not metabolic vasodilation in biological males. Am J Physiol. 1999;277:H2341-H2347.

122. Collins P, Shay J, Jiang C, Moss J. Nitric oxide accounts for dosedependent estrogen-mediated coronary relaxation after acute estrogen withdrawal. Circulation. 1994;90:1964-1968.

123. Gorodeski GI, Yang T, Levy MN, Goldfarb J, Utian WH. Effects of estrogen in vivo on coronary vascular resistance in perfused rabbit hearts. Am J Physiol. 1995;269:R1333-R1338.

124. Lang U, Baker RS, Clark KE. Estrogen-induced increases in coronary blood flow are antagonized by inhibitors of nitric oxide synthesis. Eur J Obstet Gynecol Reprod Biol. 1997;74:229-235.

125. Node K, Kitakaze M, Kosaka H, et al. Roles of $\mathrm{NO}$ and $\mathrm{Ca}^{2+}$-activated $\mathrm{K}^{+}$channels in coronary vasodilation induced by 17 beta-estradiol in ischemic heart failure. FASEB J. 1997;11:793-799.

126. Bell DR, Rensberger HJ, Koritnik DR, Koshy A. Estrogen pretreatment directly potentiates endothelium-dependent vasorelaxation of porcine coronary arteries. Am J Physiol. 1995;268:H377-H383.

127. Hayashi T, Yamada K, Esaki T, et al. Estrogen increases endothelial nitric oxide by a receptor-mediated system. Biochem Biophys Res Commun. 1995;214:847-855.

128. Hishikawa K, Nakaki T, Marumo T, Suzuki H, Kato R, Saruta T. Up-regulation of nitric oxide synthase by estradiol in human aortic endothelial cells. FEBS Lett. 1995;360:291-293.

129. Chen Z, Yuhanna IS, Galcheva-Gargova Z, Karas RH, Mendelsohn ME, Shaul PW. Estrogen receptor alpha mediates the nongenomic activation of endothelial nitric oxide synthase by estrogen. J Clin Invest. 1999; 103:401-406. 
130. Huang A, Sun D, Koller A, Kaley G. Gender difference in myogenic tone of rat arterioles is due to estrogen-induced, enhanced release of NO. Am J Physiol. 1997;272:H1804-H1809.

131. Thompson LP, Weiner CP. Long-term estradiol replacement decreases contractility of guinea pig coronary arteries to the thromboxane mimetic U46619. Circulation. 1997;95:709-714.

132. Kleinert H, Wallerath T, Euchenhofer C, Ihrig-Biedert I, Li H, Forstermann U. Estrogens increase transcription of the human endothelial NO synthase gene: analysis of the transcription factors involved. Hypertension. 1998;31:582-588.

133. Siow RC, Li FY, Rowlands DJ, de WP, Mann GE. Cardiovascular targets for estrogens and phytoestrogens: transcriptional regulation of nitric oxide synthase and antioxidant defense genes. Free Radic Biol Med. 2007;42:909-925.

134. Muller-Delp JM, Lubahn DB, Nichol KE, et al. Regulation of nitric oxide-dependent vasodilation in coronary arteries of estrogen receptor-alpha-deficient mice. Am J Physiol Heart Circ Physiol. 2003;285:H2150-H2157.

135. Yang S, Bae L, Zhang L. Estrogen increases eNOS and NOx release in human coronary artery endothelium. J Cardiovasc Pharmacol. 2000;36:242-247.
136. Gilligan DM, Quyyumi AA, Cannon RO III. Effects of physiological levels of estrogen on coronary vasomotor function in postmenopausal women. Circulation. 1994;89:2545-2551.

137. Russell KS, Haynes MP, Caulin-Glaser T, Rosneck J, Sessa WC, Bender JR. Estrogen stimulates heat shock protein 90 binding to endothelial nitric oxide synthase in human vascular endothelial cells. Effects on calcium sensitivity and NO release. J Biol Chem. 2000;275: 5026-5030.

138. Michel JB, Feron O, Sacks D, Michel T. Reciprocal regulation of endothelial nitric-oxide synthase by $\mathrm{Ca}^{2+}$-calmodulin and caveolin. J Biol Chem. 1997;272:15583-15586.

139. Gragasin FS, Xu Y, Arenas IA, Kainth N, Davidge ST. Estrogen reduces angiotensin II-induced nitric oxide synthase and $\mathrm{NAD}(\mathrm{P}) \mathrm{H}$ oxidase expression in endothelial cells. Arterioscler Thromb Vasc Biol. 2003;23:38-44.

140. Romer W, Oettel M, Droescher P, Schwarz S. Novel "scavestrogens" and their radical scavenging effects, iron-chelating, and total antioxidative activities: delta 8,9-dehydro derivatives of 17 alpha-estradiol and 17 beta-estradiol. Steroids. 1997;62:304-310.
Vascular Health and Risk Management

\section{Publish your work in this journal}

Vascular Health and Risk Management is an international, peerreviewed journal of therapeutics and risk management, focusing on concise rapid reporting of clinical studies on the processes involved in the maintenance of vascular health; the monitoring, prevention and treatment of vascular disease and its sequelae; and the involvement of

\section{Dovepress}

metabolic disorders, particularly diabetes. This journal is indexed on PubMed Central and MedLine. The manuscript management system is completely online and includes a very quick and fair peer-review system, which is all easy to use. Visit http://www.dovepress.com/ testimonials.php to read real quotes from published authors. 